ISSN: 2146-3042

DOI: $10.25095 /$ mufad.673737

\title{
Firma Performansının Kar Dağıtımına Etkisi: Sürdürülebilirlik Endeksine Tabi Firmalarda Değerlendirme*
}

Büşra DOZEN *

Tuba DERYA BAŞKAN **

\section{$\ddot{O Z E T}$}

Kurumsal sürdürülebilirlik kavramı günümüzde önemi giderek artan tartışma konularından biri haline gelmiştir ve firmaların ekonomik olarak devamlılığını etkileyen bir unsur olarak karşımıza çıkmaktadır. Kurumsal sürdürülebilirlik kavramı üzerine yapılan bu çalışmada Borsa İstanbul Sürdürülebilirlik Endeksi’ne tabi firmaların kar dă̆ıtımı yapma kararları üzerinde firma performansının bir etkisinin olup olmadı̆̆ Basit Logistik Regresyon yöntemiyle analiz edilmiştir. Çalışmanın sonucunda özkaynak oranı, stok devir hızı ve öz sermaye karlılığı değişkenleri ile kar dağıtımı arasında istatiksel olarak anlamlı ve pozitif bir ilişkinin var olduğu gözlenmiştir.

Anahtar Kelimeler: Kurumsal Sürdürülebilirlik, Kar Dağıtımı, Firma Performansı, Basit Logistik Regresyon

JEL Sinıflandirması: $M$ 40, $M 41$,

\section{THE EFFECT OF PROFIT DISTRUBITION ON FIRM PERFORMANCE:} EVALUATION IN CORPORATIVE SUSTAINBILITY

\section{ABSTRACT}

The concept of corporate sustainability has become an increasingly important topic of discussion today and is an element that affects the economic viability of firms. In this study conducted on the concept of corporate sustainability, it is analyzed by using Simple Logistic Regression method to determine whether firm performance has an effect on the profit distribution decisions of companies subject to Borsa Istanbul Sustainability Index. As a result of the study, it is observed that there is a statistically significant and positive relationship between equity ratio, stock turnover rate and equity profitability variables and profit distribution.

Keywords: Corporate Sustainability, Profit Distribution, Firm Performance, Simple Logistic

Jel Classification: $M$ 40, $M 41$

\footnotetext{
* Makale Gönderim Tarihi: 10.08.2019, Makale Kabul Tarihi: 15.08.2019, Makale Türü: Araştırma Makalesi

* 1. Kırıkkale Üniversitesi, İ̈BF, Muhasebe-Finans Anabilim Dalı, Yüksek Lisans Öğrencisi, 0000-0001-89015193, busradozen@gmail.com.

** Kırıkkale Üniversitesi, İ̇BF, Muhasebe-Finans Anabilim Dalı, Dr. Öğretim Üyesi, 0000-0001-8809-7043 tbaskan@kku.edu.tr.
} 


\section{GíRiş}

Sürdürülebilirlik kavramının kökleri Sanayi Devrimi yıllarına uzanmakta iken Dünyada sürdürülebilirlik kavramı ilk defa 1972 yılında İnsan Çevresi Konferansı'nda bahsedilmiştir.

1982 yılında Birleşmiş Milletler Çevre Kalkınma Komisyonu (WCDE) Brundtland Raporu, günümüzde kullanılan sürdürülebilirlik tanımını yapmakla birlikte kalkınma ve sürdürülebilir kalkınma kavramlarının birbirinden net olarak ayrıldığını açıklayarak sürdürülebilirliğin sosyal, ekolojik ve finansal boyutlarına vurgu yapmıştır (Khulman ve Farrington, 2010: 3436). Rapor sürdürülebilir kalkınmay1 "kendi ihtiyaçlarını karşılamak üzere; gelecek nesillerin gereksinimlerini tehlikeye atmadan bugünün ihtiyaçlarını karşılayan gelişmeler" olarak tanımlamıştır (WECD 1987).

Firmaları sürdürebilir olmaya yönelten birçok neden vardır. Fakat firmaların ticari kuruluşlar olmaları sebebiyle temel amaçları kârlılığı artırmaktır(Kuşat, 2012: 227).Ülkemizde 2014 yılında yayınlanmaya başlayan "Sürdürülebilirlik Endeksi" ile birlikte firmalara kurumsal sürdürülebilirlik açısından karşılaştırma yapabilme imkânı sağlanmıştır. Firmaların endekse olan katılımı zaman içerisinde artış göstermektedir. Endekse katılan 42 firmanın sürdürülebilir oluşunun firma performansı ve kar dağıtımı üzerinde bir etkisinin olup olmadığının araştırılması çalışmanın temel amacıdır. Yapılan basit logistik regresyon analizi sonucunda Borsa İstanbul (BİST) Sürdürülebilirlik Endeksi'ne tabi firmalarda firma performansının kar dağıtımı kararı verilmesinde anlamlı ve pozitif sonuçlar verdiği gözlenmiştir.

\section{KURUMSAL SÜRDÜRÜLEBİLİRLİK}

Sürdürülebilirlik kavramı 21. yy da tartışılmaya başlanmış olup özel-kamu sektörü açısından önemi giderek artan bir konu olarak kabul edilir (Tüm, 2012: 58).Şirket sürdürülebilirliği olarak ifade edilen kurumsal sürdürülebilirlik, firmaların var olan piyasalarda faaliyetlerini devam ettirmeyi amaçlarken gelecek kuşakların gelişmişlik düzeyinin korunabilmesi için kurumsal yönetimi tekrar düzenleme ihtiyacı doğurmuştur (Tokgöz ve Önce 2009: 249).

Kurumsal sürdürülebilirlik, firmaların hem günümüz gereksinimlerini karşılamak hem de gelecekte ihtiyaç duyabilecekleri insani ve doğal kaynakların geliştirilmesine ve korunmasına imkân tanıyan stratejiler yaratılması olarak tanımlanmaktadır (Roca ve Searcy, 2012: 103). Bir başka tanımla kurumsal sürdürülebilirlik, firmalarda ileriye dönük değerler yaratmak ve aralarındaki güvenilirliği artırmak amacıyla ekonomik çevresel ve sosyal faktörlerinin kurumsal yönetim ilkeleriyle beraber firmaların faaliyetlerinde ve karar alma aşamalarında ortaya çıkabilecek olumsuz durumların yönetilmesidir (Borsa İstanbul, 2017). Kurumsal sürdürülebilirliğin firmalar tarafından benimsenmesi, yatırımcıların daha çok ilgisini çekerek, karlılık oranlarının artmasına ve daha fazla büyüme olanaklarına sahip olmalarını sağlamaktadır. Kurumsal sürdürülebilirlik firmalara marka değeri, kurumsal itibar, maliyet azalışları ve sermaye kaynaklarına erişim kolaylığı gibi katkılar sağlamaktadır.

Ülkemizde sürdürülebilirliğe verilen önem günden güne artmaktadır. 2014 yılında kurulan Sürdürülebilirlik Endeksi'nin faydaları, kurumsal risk ve firsatlarını etkin bir şekilde 
yöneten, şirketlere rekabet avantaj sağlayan, şirketlere yeni finansman kaynakları getiren, yeni yatırım ürünleri geliştirilebilen bir endeks olarak belirtilebilmektedir. Ayrıca endeks firmalara kurumsal sürdürülebilirlik performanslarını karşılaştırma, firmaların kurumsal şeffaflık ve hesap verebilirliklerini artırma ve firmalara performans değerlendirme olanağ sunabilmektedir. Bu çalışmada, BIST Sürdürülebilirlik Endeksine tabi firmalar analiz edilerek firmaların performansları ile kar dağıtımı arasındaki ilişki incelenmiştir.

\section{LITERATÜR TARAMASI}

Konu ile ilgili literatüre bakıldığında, doğrudan kar dağıtımı ile kurumsal sürdürülebilirlik arasındaki ilişkiyi ele alan çalışmalara rastlanmamakla beraber kurumsal sürdürülebilirlik kavramının firmalar açısından önemine değinilen birçok araştırmaya rastlanmıştır. Kuşat(2012) firmalarda kurumsal sürdürülebilirlik kavramının etkin kullanılmasının rolü üzerine geniş bir literatür çalışması yapmıştır. Çalışmasında ilgili kavramı firmalariçin etkin kullanılması gereken bir kültür olarak ele almış ve firmaların karlılık, devamlılık, itibar kazanma, kurumsallığın artması gibi birçok yönde etkin kullanılacağını tespit etmiştir. Kurumsal sürdürülebilirlik ve karlılık oranları arasındaki ilişkiyi, Hindistan'dabulunan20 firma üzerinde yaptığı bir analiz ile inceleyen Aggarwal (2013), kurumsal sürdürülebilirlik ve karlılık oranı arasında negatif bir ilişkinin var olduğuna ulaşmışve firmaların vergi öncesi karı ilearalarındapozitif bir ilişki olduğunu belirtmiştir. Klettnervd. (2014) ise kurumsal sürdürülebilirlik ve kurumsal yönetim arasındaki ilişki üzerine yaptıkları çalışmada kurumsal sürdürülebilirliğin yüksek pay değerlerinin oluşturacağını gözlemlemişlerdir. Şahin ve Akgün(2016) yaptıkları çalışmada BIST Sürdürülebilirlik Endeksi'nde yer alan firmaları, ölçeğe göre sabit getiri kriteri ekseninde VZA metodu ve Malmquist Toplam Faktör Verimliliği Endeks Toplamı'nda değerlendirmişlerdir. Çalışmaları sonucunda firmaların finansal etkinlik oranlarının yıldan yıla artış olduğu sonucuna ulaşmışlardır. BIST Sürdürebilirlik Endeksi'ndeki banka harici finansal performansları ile mali yönden kurumsal sürdürebilirlik kapsamında analiz edilen yatırımcı kararları arasındaki ilişkiyi tespit etmek üzere bir çalışma yapan Kurnaz ve Kestane(2016), endeksin yeni olmasından kaynaklı veri eksikliğinden dolayı bir ilişki oluşturulamadığını belirtmişlerdir. Ancak Sürdürülebilirlik Endeksi'nin firmaların finansal performanslarında ve yatırımcı davranışlarında pozitif bir ilişki olduğunu tespit etmişlerdir.

BIST sürdürülebilirlik raporlama sistemi üzerine Özdemir ve Pamukçu(2016)tarafındanyapılançalışmada, sürdürülebilirliğin uygulanması ile ortaya çıkan geriye dönük sürdürülebilirlik raporlarının oluşması, yayın süreleri ve hazırlanan raporlarda endekse sunulan referanslar çerçevesinde bir değerlendirme yapmışlardır. Bunun sonucunda; firmaların rapor sunma oranlarında artış ve pay sahiplerinin de firmalara yönelik güven duygusunda yükseliş gözlemlenmesi ile birlikte endekse tabi yatırımların artacağını öngörmüşlerdir.BIST100 endeksinde bulunan firmaların Sürdürülebilirlik Endeksi'ne tabi olmaları durumunda firmaların karlılık oranlarında bir değişim yaratıp yaratmayacağını çoklu regresyon yöntemiyle inceleyen Önder(2017) çalışmasının sonucunda, firmaların karlılıklarında ilgili endeksin etkisinin bulunmadığını gözlemlemiştir. Wiengarten vd.(2017) kurumsal sürdürülebilirlik hakkında bilgi sahibi olan bir yöneticinin atanmasının firmanın karlılı̆̆ı üzerine etkisini 123 firmanın finansal verilerini inceleyerekirdelemiş, atanan yöneticininkarlılığı artırdığını gözlemlemişlerdir. 
Diğer taraftan finansal performansın kurumsal sürdürülebilirlik performansının asıl belirleyicisi olup olmadığı üzerine çalışma yapan Aytekin ve Erol(2018),çalışmalarında birtakım finansal oranlar ile birlikte Aras (Additive Ratio Assesment) yöntemini kullanarak BIST'te yer alan 63 firma üzerinde inceleme yapmış, firmaların finansal performans düzeyinin Sürdürülebilirlik Endeksi'nde yer bulabilmesi için yeterli bir koşul olup olmadığını tespit etmek üzere bir çalışma yapmışlardır. Çalışmaları sonucunda belirlenen dönemler açısından sürdürülebilirlik endeksinde bulunabilmek için yalnızca finansal performansın yeterli bir işaret olduğu tespit edilmiştir. Ülkemizde faaliyet gösteren firmaların sürdürülebilir yatırımları ile kurumsal finansal performansları arasında bir bağ olup olmadığ çalışma yapan Soyaş vd.(2019) farklı endüstrilerinden birçok firmanın finansal verilerini küresel veri setinden faydalanarak elde etmişler ve bu amaçla oluşturulan doğrusal regresyon tahmini ile finansal performans üzerinden olumlu etkisini kantitatif olarak gözlemlemişlerdir.

Çalışma da Kurumsal sürdürülebilirlik kavramını inceleyen pek çok çalışma incelenmiş ancak burada bir kısmına yer verilmiştir.Bu aşamada da kar dağıtımı ile ilgili kısa bir literatür çalışması yapılarak firmaların izlediği politikalar göz önüne alınmaya çalışılmıştır.

Literatürde yer alan; Cengiz vd. (2016) tarafından yapılan çalışmada, firmaların benimsemiş oldukları kar dağıtımı politikalarının kazanç yönetimi üzerinde etkisinin olup olmadığı incelenmiştir. Burada 2011-2014 yılları arasında Borsa İstanbul'da imalat sanayinde bulunan 70 firmada ihtiyari tahakkuklar üzerine Jones Modeli (1995) kullanarak kazanç yönetimi ile kar dağıtımı politikaları arasında istatiksel olarak anlamlı sonuçlar gözlemlemişlerdir. Firmasahiplik yapısının kar dağıtımı politikaları üzerindeki etkisini incelemek amacıyla Ersoy ve Çetenek(2015)yapmışolduklarıçalışmada BIST'te faaliyet gösteren 116 firmanın 2004-2009 dönemindeki verilerinikullanarakveRassal Etkili Tobit Sistem Geliştirilmiş Momentler Metodu'nu uygulayarak, sahiplik yapısının hızlı gelişen firmalarda kar dağıtımını etkilediğini gözlemlemişlerdir. Bir başka çalışmada iseBİST sanayi sektöründe yer alan 118 firmanın kar dağıtım kararları üzerinde hangi değişkenlerin etkisinin olup olmadığını Panel Veri Analiz Yöntemi ile Yıldız vd. (2014) incelemiş olup, firmaların nakit kar dağıtım kararlarında; vergi, karlık, büyüme firsatları, firma büyüklüğü, kaldıraç ve likidite değişkenlerinin etkisinin olduğunu gözlemlemişlerdir. Komrattanapanya(2013) Tayland Borsası'nda faaliyette bulunan 435 firmanın 2006-2013 verilerini Tobit Regresyon Analizi Yöntemi ile incelemiş, yapmış olduğu incelemede kar payı dağıtımına; karlılığın, likiditenin ve işletme riski parametrelerinin etkisinin olmadığını gözlemlemiştir. Asif vd.(2011)yaptıkları çalışmalarında; firmanın borçlanması ve kar dağıtımı arasındaki ilişkiyi, Pakistan Menkul Kiymetler Borsas1 100 Endeksi'ne tabi olan 403 firma üzerinde, Panel Veri Analizi Yöntemi'ni kullanarak incelemişler ve finansal kaldıraç oranının kar dağıtım kararları üzerinde anlamlı istatiksel sonuçlar verdiğini gözlemlemişlerdir.

İlerleyen kısımda Sürdürülebilirlik Endeksi'ne tabi olan firmalarda firma performanslarının kar dağıtımına etkisini incelemek üzere analiz yapılmıştır. Bu çalışma sonucunda BIST Sürdürülebilirlik Endeksi'ne tabi firmaların kar dağıtımını etkileyen faktörler incelenerek literatüre katkı yapmak amaçlanmıştır. 


\section{VERİ VE YÖNTEM}

\subsection{Modelin Varsayımları ve Uyum İyiliği Testi}

Logistik regresyon analiz yöntemi doğrusal olmayan bir analiz olup, logistik regresyondaki anahtar kavram "logit" kavramıdır. Logit, olasılıklar oranının logaritmasıdır.

Logistik regresyon modeli aşağıdaki gibi yazılmaktadır.

$$
\operatorname{Logit}(\mathrm{p})=\log \frac{\mathrm{p}}{\mathrm{p}-1}=\mathrm{X}^{1} \beta+\mathrm{u}
$$

Burada $\mathrm{p}$ gerçeğe uygun değer yöntemi, $\mathrm{p}-1$ gerçeğe uygun değerin kullanılmamas1 durumunu, $\mathrm{u}$ ise hata terimini ifade eder (Ural vd.2015: 90).

Logistik analize göre (Baydemir, 2014: 27);

$\mathrm{Bu}$ yöntem benzer istatiksel yöntemlere göre daha az varsayım gerektiren esnek bir yöntemdir. $\mathrm{Bu}$ yöntemde bağımsız değişkenlerin normal dağılmaları, aralarındaki ilişkinin doğrusal olması veya farklı kategorilerin eşit varyanslı olmaları gibi zorunluluklar yoktur. daha kolaydir.

Logistik modelde model doğrusal hale getirildiği için modelin çalıştırılması

Logistik regresyonda negatif olasılıkla karşılaşma sorunu olmaz.

Logistik analiz yöntemine göre üç yöntem bulunmaktadır.

- Basit Logistik Regresyon Yöntemi,

- Çoklu Logistik Yöntemi,

- $\quad$ İsimsel Logistik Yöntemi,

Çalışmada "Basit Logistik Regresyon Yöntemi (İkili- Binary)"kullanılmıştır. Basit logistik regresyon yöntemine göre bağımlı değişkene iki değer verilerek bağımsız değişken değerleri olasılıklar ile tespit edilmeye çalışılmaktadır. Yani Basit Logistik Regresyon Analizi Yöntemi, bağımlı değişkenin iki kategorili olduğu durumlarda gerçekleştirildiği ve bağımlı değişkenin gruplara ayrılarak, bu gruplardan birine 0 diğerine 1 şeklinde kodlama yapıldığ 1 yöntemdir. (Kocabaş, 2014: 14).

$Y=\{1$, Kar Dağıtan firmalara; 0, Kar Dağıtımı Yapmayan Firmalara $\}$.

İki kategorili Y bağımlı değişkeni, bağımsız değişkenlerin en iyi doğrusal kombinasyonunun doğrusal olmayan bir fonksiyonuna dayanarak,

$$
\mathrm{Y}=\mathrm{u} \beta_{0}+\beta_{1} \mathrm{X}^{1} 1+\beta_{2} \mathrm{X}^{2}+\cdots+\beta_{\mathrm{n}} \mathrm{X}^{\mathrm{n}} 1+\mathrm{u} \text { doğrusal denklemi elde edilmektedir. }
$$




\subsection{Araştırma Hipotezleri ve Değişkenleri}

Çalışmada Kurumsal Sürdürülebilirlik Endeksi'ne tabi firmaların kar dağıtımı ile firmaların borçlanma oranı, stok oranı ve firmaların performansı arasındaki ilişki incelenmiştir. Yani Kurumsal Sürdürülebilirlik Endeksine tabi firmaların kar dağıtımı yapmasında etkili olan bazı faktörler tespit edilmeye çalışılmıştır. Basit logistik regresyon yöntemi yardımıyla 2014-2017 yılları arasında 42 adet Sürdürülebilirlik Endeksi'ne tabi firmada kar dağıtımını etkileyen bir takım faktörler incelenmiştir. Aşağıdaki Tablo 1'de araştırmanın hipotezleri gösterilmiştir.

Tablo 1. Araştırma Hipotezleri

\begin{tabular}{|l|}
\hline H1: Firmaların performansı kar dağıtımını etkilemektedir. \\
\hline H2: Firmaların sahip olduğu sermaye kar dağıtımını etkilemektedir. \\
\hline H3: Firmaların stoklarının elden çıkarılma hızı kar dağıtımını etkilemektedir. \\
\hline H4: Firmaların aktiflerinin elden çıkarılma hızı kar dağıtımını etkilemektedir \\
\hline H5: Firmaların borçlanma durumu kar dağıtımını etkilemektedir. \\
\hline
\end{tabular}

Hipotezlerin test edilmesi için bir takım rasyolar kullanılmıştır. Bu rasyolar aşağıdaki tabloda belirtilmiştir (Akgüç, 2012). Bu firmaların verilerine kendi web sitelerinden ve Kamuyu Aydınlatma Platformu'ndan (KAP) ulaşılmıştır. Çalışmada kar dağıtan yapan firmalara " 1 "kar dağıtımı yapmayan firmalara "0" değeri verilerek bağımlı değişken belirlenmiştir. Aynı zamanda çalışmada kukla değişken olarak aktif devir hızı, stok devir hızı ve sermaye yapısı değişkenleri kullanılmıştır.Bu değişkenler aşağıdaki Tablo 2 de gösterilmiştir.

Tablo 2. Araştırma Değişkenleri

\begin{tabular}{|l|l|l|l|}
\hline Arşt. Değişkenleri & Kısaltmalar & Hesaplamalar & Alındığı Yer \\
\hline Firma Performansı & Roa & Net Kar/Toplam Varlık & KAP \\
\hline Firma Performansı & Roe & Net Kar/Öz sermaye & KAP \\
\hline Sermaye Yapısı & Ozko & Özkaynak/ Toplam Varlık & KAP \\
\hline Stok Devir Hızı & Sdh & $\begin{array}{l}\text { Satılan Mal Maliyeti } \\
\text { (Dönem başı stok + Dönem Başı Stok) / 2 }\end{array}$ & KAP \\
\hline Aktif Devir Hızı & Adh & Net Satışlar/ Toplam Varlık & KAP \\
\hline Kaldıraç oranı & Tyk & Toplam Yabancı Kaynak / Toplam Varlık & KAP \\
\hline
\end{tabular}

Değişkenler tespit edildikten sonra çalışmada uygulanan basit logistik regresyon modeli aşağıdaki şekilde oluşturulmuştur.

$$
\mathrm{KD}_{\mathrm{it}}=\beta_{0}+\beta_{1} \text { roa }_{\mathrm{it}}+\beta_{2} \text { roe }+\beta_{30 z k o}{ }_{\text {it }}+\beta_{4} \mathrm{sdh}_{\text {it }}+\beta_{5} \mathrm{adh}_{\text {it }}+\beta_{6} \mathrm{tyk}_{\mathrm{it}}+\mathrm{u}_{\mathrm{i}},
$$

\subsection{Bulgular ve Sonuçlar}

Stata14.1 programı ile iki kategorili bağımlı değişken ile farklı tür ve sayıda kategorilere sahip beş bağımsız değişken Logistik Regresyon Analizi'ne tabi tutulmuştur. Yukarıdaki modelin geçerli olması için $\mathrm{R}^{2}$ değerinin 0 İle 1 arasında olması gerekmektedir ve olasılık değerinin 0,05' in altında olması yeterlidir (Çemrek ve Burhan, 2014: 55). 
Modelin kabul edilip edilemeyeceğine ilişkin bir takım testler yapılarak sınır değerler tespit edilmelidir. Modelin Uyum İyiliği (Goodness of Fit Statistics) denilen bu tespitler ile bağımlı değişkeni en iyi şekilde açıklamak için, oluşturulan modelin etkinliğinin ölçüsünü göstermektedir. $\mathrm{Bu}$ ölçütlerden biri olan Hosmer-Lemeshow testi bu çalışmada uygulanmaktadır (Hosmer ve Lemeshow, 2000:156). Bu test, Lojistik Regresyon Modeli'nin bir bütün çerçevesinde uyumunu değerlendirmektedir. Küçük örneklemlerle çalışıldığında güçlü bir testtir. Bu teste ilişkin sonucu yorumlarken prob $(\mathrm{p})$ değerinin 0.05 den büyük olması yani sonucun anlamlı olmaması gerekmektedir. Yani değerin 0'a yaklaşması uyumun az olduğunu göstermektedir. dolayısı ile modelin uygun olmadığına ve tahmin edilen değerler ile gözlenen değerler arasında anlamlı bir farklılık olmadığını göstermektedir. Nihayetin de modelin uygunluğu için model ile değerler arasında anlamlı bir fark olmamalıdır (Garson, 2008).

Çalışmadaki modelde Hosmer ve Lemeshow Testi uyum iyiliği testine göre Prob değeri=0,1038 çıkmış ve 0.05 den büyük çıktığ 1 için model uygulanabilir olarak tespit edilmiştir.

Tablo 3. Basit Logistik Analizi Sonuçları

\begin{tabular}{|l|l|l|}
\hline Değişkenler & Olasılık Oranı & Standart hata \\
\hline roa & $0.6197943 \quad(0.864)$ & 1.736379 \\
\hline roe & $0.1937 .188(0.000)^{*}$ & 4025.434 \\
\hline tyk & $0.1380755(0.005)^{* *}$ & .0964688 \\
\hline ozko & $86.54138 \quad(0.000)^{*}$ & 93.0629 \\
\hline sdh & $1.018392 \quad(0.03)^{* *}$ & 0.0087176 \\
\hline adh & $0.9534528 \quad(0.144)$ & 0.0310845 \\
\hline Loglikelihood & -68.752926 & \\
\hline Wald chi2(6) & 43.53 & \\
\hline F İstatistiği Olasılık & $(0.000)^{*}$ & \\
\hline Gözlem Sayıs1 & 168 & \\
\hline
\end{tabular}

*0.01, ** 0.05, anlamlılık düzeyleri (Bağımlı Değişken: Karlılık Dağıtımı).

Modelin bütünüyle istatistiksel olarak anlamlı olup olmadığını saptamak için uygulanan F testinin sonucu incelediğinde, istatistik değerinin anlamlılık düzeyini gösteren olasılık değerinin 0.000 olduğu görülmüştür. Buna göre aşağıdaki sonuçlar tespit edilmiştir:

- Net Kar/Toplam Varlık (roa) değişkeni katsayı değeri 0,6197943 ve olasıllk değerinin 0.864 olarak belirlenmiştir. Bu sonuca göre $\% 1, \% 5$ ve $\% 10$ anlamlılık düzeyinde bakıldığında Net Kar/Toplam Aktif ile kar dağıtımı arasında anlamlı ve pozitif bir ilişki bulunmamaktadır.

- Net Kar/Öz sermaye (roe) değişkeni katsayı değeri 19,37 ve olasılık değerinin 0.000 olarak belirlenmiştir. Bu sonuca göre $\% 1, \% 5$ ve $\% 10$ anlamlılık düzeyinde bakıldığında Net Kar/Öz sermaye ile kar dağıtımı arasında anlamlı ve pozitif bir ilişki bulunmaktadır. 
- Özkaynak/Toplam Varlıkdeğişkeninin katsayısı değeri86.54138ve olasılık değeri 0.000 olarak belirlenmiştir. $\mathrm{Bu}$ sonuca göre $\% 1$ anlamlılık düzeyinde Özkaynak/Toplam Varlık'daki bir birimlik artış, kar dağıtımı kullanımını 86.54138birim artırmaktadır. Başka bir deyişle Özkaynak/ Toplam Varlık ile kar dağıtımı arasında anlamlı ve pozitif bir ilişki vardır.

- Stok devir hızı değişkeninin katsayı değeri1.018392 ve olasılık değeri 0.033 olarak belirlenmiştir. $\mathrm{Bu}$ sonuca göre $\% 5$ anlamlılık düzeyinde bakıldığında stok devir hızı ile kar dağıtımı arasında anlamlı ve pozitif bir ilişki bulunmaktadır.

- Aktif devir hızı değişkeni 0,9534528 ve olasılık değerinin 0.144 olarak belirlenmiştir. Bu sonuca göre $\% 1, \% 5$ ve $\% 10$ anlamlılık düzeyinde bakıldığında aktif devir hızı ile kar dağıtımı arasında anlamlı ve pozitif bir ilişki bulunmamaktadir.

- Sermaye Yapısı değişkenini ölçen Özkaynak/Toplam Varlık değişkeninin, katsayı değeri 0, 1380755 ve olasılık değeri0.005 olarak belirlenmiştir. Bu sonucuna göre \% 5 anlamlılık düzeyinde Özkaynak/Toplam Varlık bir birimlik artış,kar dağıtımını 0, 1380755 birim artırmaktadır. Başka bir deyişle sermaye yapısı ile kar dağıtımı arasında anlamlı ve pozitif bir ilişki vardır.

$\mathrm{Bu}$ sonuçlara göre hipotezlerimizin sonuçları da aşağıdaki gibi tespit edilmiştir.

Tablo 4. Hipotez Sonuçları

\begin{tabular}{|l|l|}
\hline H1: Net Kar/Öz sermaye (roa) kar dağıtımını etkilemektedir. & Red edildi. \\
\hline H2: Özkaynak/Toplam Aktif (roe) kar dağıtımını etkilemektedir. & Kabul edildi. \\
\hline H3: Firmaların sahip olduğu sermaye kar dağıtımını etkilemektedir. & Kabul edildi. \\
\hline H4: Firmaların stok devir hızı kar dağıtımını etkilemektedir. & Kabul edildi. \\
\hline H5: Firmaların aktiflerinin devir hızı kar dağıtımını etkilemektedir. & Red edildi. \\
\hline H6: Firmaların borçlanma durumu kar dağıtımını etkilemektedir. & Kabul edildi. \\
\hline
\end{tabular}

Hipotez sonuçlarından sonra bağımsız değişkenlerin anlamlılığını sınayabilmek için yaptığımız Wald Testi kullanılmaktadır. Wald Testi ile bağımsız değişkenlerin anlamlılıklarını değerlendirdiğimizde; kaldıraç oranı, stok devir hızı, aktif devir hızı ve firma performansı değişkenlerinin değişim oranlarının \%43.53 olduğu tespit edilmiştir. $\mathrm{Bu}$ doğrultuda istatiksel olarak anlamlı kabul edilen değişkenler için de en son olarak marjinal etkilerine göre kar dağıtımı değiştirme olasılığı Tablo 5'de göstermektedir.

Tablo 5. Değişkenler İçin Marjinal Etkiler

\begin{tabular}{|l|l|l|l|l|}
\hline Değişkenler & dy/dx & Standart hata & z & p \\
\hline roe & 0,9950206 & 0,2330185 & 4,27 & 0,000 \\
\hline ozko & 0,586394 & 0,1125439 & 5,21 & 0,000 \\
\hline sdh & 0,0023958 & 0,0010754 & 2,23 & 0,026 \\
\hline tyk & $-0,2602851$ & 0,0841629 & $-3,09$ & 0,002 \\
\hline
\end{tabular}

Kurumsal sürdürülebilirlik endeksine tabi firmalarda; anlamlı kabul edilen değişkenlerin, marjinal etkilere göre kar dağıtımını değiştirme olasılığını göstermektedir. Net Kar/Özsermayede bir birimlik artış, kar dağıtımını 0,9950206 birim artırmakta; Öz kaynak/ Top Varlık oranındaki bir birimlik artış, kar dağıtımını 0,586394 birim artırmakta; Stok Devir 
Hızındakibir birimlik artış kar dağıtımını 0,0023958 birim artırmakta ve Toplam Yabancı Kaynak / Öz Sermaye oranındaki bir birimlik artış kar dağıtımını -0,2602851 birim azaltmaktadır.

\section{SONUÇ}

BIST Sürdürülebilirlik Endeksi'nin hesaplanmasıyla beraber firmalar açık ve şeffaf hale gelmiş, endekse tabi olan firmalara güven artmış ve sermaye yatırımlarının da daha çok bu firmalara yapıldığ gözlemlenmiştir. Borsa İstanbul tarafından 2014 yılında yayınlanmaya başlayan bu endeks; ekonomik, çevresel, sosyal vb.konularda sürdürülebilirliğe nasıl daha da yaklaşıldığını gösterir. 2018 yılı itibari ile 50 firmanın sürdürülebilirlik endeksinde yer aldığ belirlenmiş ve bu firmalarda, firma performanslarının kar dağıtımı üzerine etkisinin olup olmadığı araştırılmaya çalışılmıştır. Ayrıca kukla değişken olarak modele aktif devir hızı ve stok devir hızı ile sermaye yapısı da ilave edilerek basit logistik regresyon analiz yöntemi kullanılmıştır.

Modelde kar dağıtımı bağımlı değişken olarak kullanılırken, aktif karlılık oranı ve öz sermaye karlılık oranı bağımsız değişkenler olarak kullanılmıştır. Modele ayrıca kukla değişken olarak da devir hızı, sermaye yapısı ve kaldıraç oranı dâhil edilmiştir.

Analiz sonucunda öz kaynak oranı, stok devir hızı ve öz sermaye karlılığı ile kar dağıtımı aralarında istatiksel olarak anlamlı ve pozitif ilişkinin var olduğu tespit edilirken; aktif devir hızı ve aktif karlılık değişkenlerinin ise kar dağıtımı ile aralarında bir ilişki bulunamamıştır. Analiz sonuçlarına göre firmaların borçlanma durumları, sahip olduğu sermaye, stok devir hızı ve öz sermaye karlılığı firmaların kar dağıtımı kararlarını etkilediği sonucuna ulaşılmış; aktiflerin karlılığı ve aktiflerinin devir hızını kar dağıtımı kararını etkilemediği sonucuna ulaşılmıştır. Ulaşılan sonuca göre aktiflerin devir hızlarının, kar dağıtımını etkilememesi, doğrudan satışların kar marjı ile satılmamasından ya da satışlardan sağlanan gelirlerin başka şekilde değerlendirilmesine bağlayabiliriz. Diğer taraftan aktif karlılık oranı ile de kar dağıtımı arasında bir ilişki tespit edilememiştir. Anlamsız çıkan her iki sonucun aktifler üzerinde tespit edilen oranlar olması firmaların kar dağıtımında firma varlıklarından ziyade başka unsurları göz önüne aldıkları tespit edilmiştir.

Sonuçta kurumsal Sürdürülebilirlik Endeksi'ndeki firmalarda, firmaların borç oranlarının azalması, sermaye miktarlarının artması ve ellerinde bulunan stokların hızla paraya çevrilebiliyor olmasının firmaların kar dağıtımı kararı almasını etkilediği sonucuna ulaşılmıştır. Bu firmaların ileriye dönük değerler yaratması ve güvenilirliğinin artırması, kar dağıtım kararlarında da genel anlamda güvenilirliği artırdığını söyleyebiliriz.

\section{KAYNAKLAR}

Aggarwal, Priyanka (2013), "Impact of Sustainability Performance of Company on its Financial Performance: A Study of Listed Indian Companies", Global Journal of Management and Business Research, 13, 11, pp. 60.

Akgüç, Öztin (2017), Mali Tablolar Analizi, 16. Baskı, Arayış Yayınevi, İstanbul. 
Asif, Aasia- Rasool, Wagas - Kama, Yasir (2011), "Impact Of Financial Leverage On Dividend Policy: Empirical Evidence From Karachi Stock Exchange-Listed”, African Journal Of Business Management, 5, 4, pp. 1312-1324.

Aytekin, Sinan - Erol, A. Ferit (2018), "Finansal Performans Kurumsal Sürdürülebilirlik Performansının Temel İktisadi ve İdari İncelemeler Dergisi, 17, ss. 869 - 886.

Aytekin, Sinan - Erol, A. Ferit (2013), "BIST de İşlem Gören Gıda İşletmelerinin TOPSIS Yöntemi İle Finansal Performanslarının Değerlendirilmesi”, Yönetim ve Ekonomi Araştırmaları Dergisi, 21, ss. 30-47.

Baydemir, M. Bedir (2014), “Lojistik Regresyon Analizi Üzerine Bir İnceleme”,Yüksek Lisans Tezi, İnönü Üniversitesi Sosyal Bilimler Enstitüsü, Malatya.

Borsaİstanbul(2017).http://www.borsaistanbul.com/endeksler/bist-pay endeksleri/surdurulebilirlik-endeksi, (28.08.2017).

Cengiz, Selim - Dilsiz, M. Şükrü - Aslanoğlu, Suphi (2016), "Kar Dağıtım Politikasının Kazanç Yönetimi Uygulamaları Üzerindeki Etkisi”, Muhasebe ve Finansman Dergisi, 70, ss. 39-54.

Çemrek, Fatih - Burhan, Emine (2014), "Petrol Tüketiminin Ekonomik Büyüme Üzerindeki Etkisinin Panel Veri Analizi İle İncelenmesi: Avrupa Birliği Ülkeleri ve Türkiye Örneğì", Uluslararası Alanya İşletme Fakültesi Dergisi, 6, 3, ss. 47-58.

Ersoy, Ersan - Çetenak, Emin (2015), “Sahiplik Yoğunlaşmasının Temettü Dağıtım Kararlarına Etkisi: Borsa İstanbul'da Bir Uygulama", Ege Akademik Bakış Dergisi, 15,4 , ss. 509-521.

Garson, G. D. (2008), "Logistic Regression”, http://www.chass.ncsu.edu/garson/ PA765/ logistic.htm.

Hosmer, W. David - Lemeshow, Stanley (2000), “Applied Logistic Regression”, John Wiley and Sons, NewYork.

Klettner, Alice - Clarke, Thomas - Boersma, Martjn (2014), "The Governance Of Corporate Sustainability: Empirical Insights İnto The Development, Leadership And Implementation Of Responsible Business Strategy”, J.Bus Ethics, 122, pp. 145-165.

Komrattanapanya, Pornumpai - Suntraruk, Phassawan (2013), "Factors Influencing Dividend Payout in Thailand: ATobit Regresyon Analysis", International Journal of Accounting and Financing Reporting, 3, 2, pp. 255-268.

Kuşat, Nurdan (2012), "Sürdürülebilir İşletmeler İçin Kurumsal Sürdürülebilirlik ve İçsel Unsurları”, Afyon Kocatepe Üniversitesi, İİBF Dergisi, 14, 2, ss. 227-242.

Kurnaz, Niyazi - Kestane, Ali (2016), "Kurumsal Sürdürülebilirliğin Ekonomik Açıdan İncelenmesinde Yatırımcı Davranışları İlişkisi: Bıst Sürdürülebilirlik Endeksinde Bir Uygulama", Sosyal Bilimler Dergisi, 49, ss. 278-302. 
Kuhlman, Tom - Farrington, Jhon (2010), "What is Sustainability? ”, Sustainability, 2, 11, pp. 3436-3448.

Kuzucu, Narman (2015), "Determinants of Dividend Policy: A Panel Data Analysis for Turkish Listed Firms", International Journal of Business and Management, 10, 11, pp.149-160.

Önder, Şerife (2017), “İşletme Karlılığına Kurumsal Sürdürülebilirliğin Etkisi: Bist’te Bir Uygulama”, Muhasebe Bilim Dünyası Dergisi, 19, 4, ss. 937-956.

Özdemir, Zehra ve Pamukçu, Fatma (2016), "Kurumsal Sürdürülebilir Raporlama Sisteminin Borsa İstanbul Sürdürülebilirlik Endeksi Kapsamındaki İşletmelerde Analizi”, Mali Çözüm Dergisi, 134, ss.13-35.

Roca, L. Clement - Searcy, Cory (2012), “An Analysis of Indicators Disclosed in Corporate Sustainability Reports”, Journal of Cleaner Production, 20, pp. 103-118.

Şahin, İ. Erdem - Akgün, Ali (2016), "BIST Sürdürülebilirlik Endeksinde Faaliyet Gösteren Şirketlerin Finansal Etkinliklerinin Analizi”, Journal of Economics, Finance and Accounting, 3, 4, ss. 355-369.

Tokgöz, Nuray - Önce, Saime (2009), "Şirket Sürdürülebilirliği: Geleneksel Yönetim Anlayışına Alternatif ", Afyon Kocatepe Üniversitesi, İktisadi ve İdari Bilimler Fakültesi Dergisi, 11, 1, ss. 249-272.

Tüm, Kayahan (2014), “Kurumsal Sürdürülebilirlik ve Muhasebeye Yansımalar”, Akademik Yaklaşımlar Dergisi, 5, 1, ss. 58-81.

Ural, Kerem - Gürarda, Şevin - Önemli, M. Burak (2015), "Lojistik Regresyon Modeli İle Finansal Başarısızlık Tahminlemesi: Borsa İstanbul' da Faaliyet Gösteren Gıda, İçki ve Tütün Şirketlerinde Uygulama”, Muhasebe ve Finansman Dergisi, 67, ss. 85-100.

Wiengarten, Frank - Chris K.Y. Lo - Jessie L.Y. K. Lam. (2017). "How does Sustainability Leadership Affect Firm Performance? The Choices Associated with Appointing a Chief Officer of Corporate Social Responsibility", Journal of Business Ethics, 140, 3, pp. 477-493.

WCED (World Commission on Environment and Development), (1987), Our Common Future, Report Of The World Commission On Environment And Development, Oxford University Press, U.K.

Yıldız, Berk - Gökbulut, R. İlker - Korkmaz, Turhan (2014), "Firmalarda Temettü Politikalarını Etkileyen Unsurlar: BİST Sanayi İşletmeleri Üzerine Bir Panel Veri Uygulaması", Ekonomik ve Sosyal Araştırmalar Dergisi, 10,10, ss.185-206. 
